\title{
Various Hormonal Supplementations Activate Sugarcane Regeneration In-Vitro
}

\author{
Ghulam Zahra Jahangir \& Idrees Ahmad Nasir \\ National Centre of Excellence in Molecular Biology, Punjab University, Lahore, Pakistan \\ E-mail: dr.idrees@gmail.com \\ Riaz Ahmad Sial \& Muhammad Aslam Javid \\ Agriculture Biotechnology Institute, Ayub Agricultural Institute, Faisalabad, Pakistan \\ E-mail: quasem92@yahoo.com \\ Tayyab Husnain \\ National Centre of Excellence in Molecular Biology, Punjab University, Lahore, Pakistan
}

\begin{abstract}
Influence of different hormonal concentrations in plant growth medium on the onset of callus and somatic embryoid induction chased by plantlet regeneration and multiplication of regenerated shoots was the main goal of these studies. Results concluded that MS medium supplemented with auxin alone ( 3 to $4 \mathrm{mg} / 12$, 4-D) induces callus formation (3mg/1 2, 4-D alone produced embryogenic calli) and auxin-cytokinin combination like 2, 4-D and IAA (both in $1 \mathrm{mg} / 1$ and $2 \mathrm{mg} / 1$ concentration) with BAP (1mg/l) found very effective for somatic embryoid induction. Plantlet regeneration from embryogenic calli, as somatic embryogenesis, found good in auxin-cytokinin combination of 2, 4-D and IAA with BAP but in different concentrations i.e. 2, 4-D and IAA $2 \mathrm{mg} / \mathrm{l}$ with 2 and $3 \mathrm{mg} / \mathrm{l}$ BAP.
\end{abstract}

Keywords: Saccharum oficinarum, Tissue culture, Callogenesis, Somatic embryogenesis

Abbreviations: 2, 4-D (2, 4-Dichlorophenoxy Acetic Acid), IAA (Indole Acetic Acid), BAP (Banzyle Amino Purine), MS (Murashige and Skoog) Basal Medium.

\section{Introduction}

Sugarcane (Saccharum oficinarum) is a perennial member of Gramineae family. Besides sugar and 'Gur', ethanol is being produced from sugarcane for domestic and export purpose as well.

There is a dire need to increase sugarcane productivity and quality enhancement as Pakistan occupies fifth position in cane producing countries and fifteenth one among sugar producing countries (http:/www.thebioenergysite.com/articles/33 5/pakistan-sugar-annual-report-2009). Despite the great demand, the desired production target per acre yield and quality improvement of sugarcane have not achieved yet. Moreover, lack of quality research and crop disease control measures manifold the problem. As sugarcane is a vegetatively propagated crop, it is vulnerable to pathogens and gets diseased during seed preparation and transportation practices. The present project was aimed to develop disease free germplasm of well adopted sugarcane cultivars being grown in Pakistan.

Plant tissue culture techniques like micropropagation and somatic embryogenesis can be used for successful sugarcane propagation by controlling a lot of problems which are faced during conventional breeding practices. The technique ensures disease free multiplication of elite varieties (khan et al., 2006) and minimizes time span required for mass production.

The present project was aimed to develop disease free germplasm of well adopted sixteen sugarcane cultivars being grown in Pakistan (Table-1). The protocol for regeneration of plantlets through indirect somatic embryogenesis was optimized for genetic improvement of sugarcane germplasm against Sugarcane Mosaic Virus. 


\section{Materials and Methods}

Indirect Somatic embryogenesis was selected for its overwhelming advantages over direct regeneration. The former produces plenty of plants at a time which is its most considerable gain. The source plants were taken from fields of National Centre of Excellence in Molecular Biology, University of the Punjab, Lahore. Thin slices were cut from inner immature leaf whorls and used as explants. Outer leaf whorls removed in sterile zone up to $0.7 \mathrm{~cm}$ diameter of stalk and approximate length of $8-10 \mathrm{~cm}$ from base at node to up at internode and once swabbed with each of $0.01 \%$ mercuric chloride, absolute ethanol and autoclaved distilled water. Remaining whorls were also removed until stalk remained only $0.3-0.4 \mathrm{~cm}$ thick and $4-5 \mathrm{~cm}$ long then it was cut into slices of $0.2-0.3 \mathrm{~cm}$ long and cultured on growth medium. Sterilization of growth medium was achieved by autoclaving at $121{ }^{\circ} \mathrm{C}$ and $105 \mathrm{KPa}$ for 20 minutes. Incubation conditions were optimized at $16 \mathrm{hrs}$ photoperiod of approximately 1000 lux alternating with $8 \mathrm{hrs}$ of dark at $23 \pm 2^{\circ} \mathrm{C}$.

Growth medium used for induction of callus, somatic embryoids and for plant regeneration was same except hormonal supplementation. It contained 4.43g/l MS medium based on Murashige and Skoog's (1962) basal medium (MS SIGMA, M 5519) with 3\% sucrose, $0.3 \%$ phytagel as gelling agent and $\mathrm{pH}$ maintained at 5.5 to 5.8 (with 1.0 normal $\mathrm{HCl}$ and $\mathrm{NaOH}$ ). For callogenesis four auxin concentrations (Table-2) were tested. For somatic embryogenesis and plant regeneration, calli were subjected to eight auxin-cytokinin combinations (Table-2).

Callus cultures were kept under complete darkness for first three weeks and on induction of somatic embryoids were exposed to $16 / 8 \mathrm{hrs}$ light/dark conditions. Callus cultures were maintained in disposable sterile Petri plates and on regeneration of plantlets the cultures were shifted and maintained in test tubes. Cultures were subcultured and transferred to fresh medium after every 15 days. Time taken to induce callus, somatic embryoids and plantlet regeneration in specific hormonal supplementation was recorded (in days) on daily basis inspection.

\section{Results and discussion}

According to the skeleton of experiment the results observed are presented in succession.

\section{Callogenesis:}

The four concentrations of 2, 4-D used for callus induction were $(1.0,2.0,3.0$, and 4.0mg/l). A specific supplementation was considered more or less suitable on the basis of time (in days) the explant took to onset the process of callus formation with appearance of minute nodule like cellular mass at cut edges (Figure $4 \mathrm{a} \& \mathrm{~b}$ ) of explant; from the day of inoculation. On all supplementations different varieties produced calli of different forms like tough, compact, nodular, friable and soft foam like, and of varying shades like greenish yellow, fresh yellow, pale yellow and even in some golden yellow and whitish in shade. Although no generalization was concluded yet tough, compact and yellow calli with whitish shade were good embryogenic. All varieties showed approximately similar and good results with $3.0 \mathrm{mg} / 1$ and $4.0 \mathrm{mg} / 1$ 2,4-D supplementations but best in former among all varieties. (Figure 1depicts the lowest values of time (mean number of days) taken to induce callus formation in SC-3 and SC-4). Medium with 2,4-D 3.0mg supplementation was recorded most efficient as it induced the explant to be changed into callus (a mass of undifferentiated cells; Figure $4 \mathrm{c} \&$ d) completely but others were observed slightly less effective as the conversion was comparatively slow and incomplete. It was observed in all cultivars that within a period of six to nine weeks the piece of explant cultured had developed into callus tissue completely, even embryo induction (whitish shade) was also observed in some varieties on same supplementation but this was not the case with any other concentration (like 2,4-D 2.0 or $4.0 \mathrm{mg} / \mathrm{l}$ ).

Many scientists have used 2,4-D for callus formation and found effective like Athar, A. et al (2009) obtained $100 \%$ callus induction in $3.0 \mathrm{mg} / \mathrm{L}$ of 2,4-D. Badawy, O. M et al (2008) and Gandonou et al (2005) also obtained embryogenic callus from leaf bases at 3mg/l 2,4-D. Ramanand et al (2005) observed maximum percentage of callus induction from leaf sheath explants within 10-14 days at 2,4-D 4.0mg/l. Alam et al (2003) also produced callus from leaf sheath at $4.0 \mathrm{mg} / 1$ concentration of 2,4-D.

Some other researchers have reported variety of callus colors and texture types (forms) in many varieties of sugarcane on different media like Anbalgan et al; (2000) reported two types of callus (one loose, friable and embryogenic other compact, white, nodular and embryogenic). Fitch and Moor (1990) observed white, nonregenerative and green, regenerative callus. Escalona et al; (1995) found compact and nodular callus forms.

\section{Somatic embryogenesis and plantlet regeneration:}

Some compact calli were whitish in shade and embryogenic while their white appearance was because of presence of somatic embryoids (Figure 4g), in some even before transfer to embryogenic medium. Five week old calli were selected and subjected to embryogenic media (containig auxins and cytokinins in combinations, Table-2) to investigate the role of hormonal combinations. Most selection was made from SC3 as the calli were 
compact and embryogenic which supported somatic embryoids and persuaded by plantlet regeneration from them. Among different combinations used 2,4-D+BAP and IAA+BAP both in 1+1,2+1 showed excellent results (SS1 \& SS5, SS2 \& SS6 respectively in Figure 2) as the white granule like somatic embryoids (Figure 4g) assured appearance within one to two weeks after transfer. Minute plantlets were observed to be regenerated from nodular structure (Figure $4 \mathrm{~h}$ ) within three weeks of transfer to hormonal combination as described in Table-2. Among all concentrations $2,4-\mathrm{D}+\mathrm{BAP}$ and IAA+BAP both in $2+2$ and $2+3$ showed very good results as the whole of the callus tissue supported plenty of plants (Figure $4 \mathrm{i}, \mathrm{j}$ ) in all varieties with no exception but in some varieties growth was late and slow (SS3 \& SS7, SS4 \& SS8 respectively in Figure 3). A general behavior noted was that high auxin concentration in combination supported callus proliferation and embryo induction but high level of cytokinin in combination supports plant regeneration.

Review of related research by other workers also supports the presented results. Ali et al; (2007) reported indirect somatic embryogenesis on auxin-cytokinin combination and found best results in 2,4-D +BAP $(1+0.25 \mathrm{mg} / \mathrm{l})$ in CP 77,400 and BL-4 (1+0.5mg/l). Manickavasagam and Ganapathi (1998) also reported best effect of auxin-cytokinin interaction (2,4-D+BAP) on somatic embryogenesis and plant regeneration in sugarcane variety Co 671 . They obtained best results with $2,4-\mathrm{D}+\mathrm{BAP}$ in concentration of $2+1 \mathrm{mg} / \mathrm{l}$. Ho and Vasil (1983) observed that many embryoids (somatic embryos) were formed when the callus was allowed to remain on the high 2,4-D medium for a prolonged period. They reported somatic embryogenesis from embryogenic callus formed from segments of young leaves cultured on MS supplemented with auxin-cytokinin combination (0.53 mg/1 2,4-D, 5\% coconut milk). Nadar et al; (1978) raised embryogenic callus on MS with 3.0 $\mathrm{mg} /$ liter 2,4-D and suggested that the process of dedifferentiation and embryogenic-cell initiation required relatively high auxin concentrations. They further found that auxin concentrations may be required for advanced embryogenesis stages. According to literature on HEC website (http://prr.hec.gov.pk/Chapters/1 370-5), lower 2, 4-D (auxin) concentration i-e. 1.0 or $0.5 \mathrm{mg} / 1$ does not support somatic embryogenesis rather at $1.5-3.0 \mathrm{mg} / 1$ induces up to $80 \%$ somatic embryogenesis.

\section{References}

Alam, R., Mannan, S.A., Karim, Z. \& Amin, M.N. (2003). Regeneration of sugarcane (Sacchrum oficinarum) plantlet from callus. Pakistan Sugar Journal, 18, 15-19.

Ali, A., Naz, S. \& Iqbal, J. (2007) Effect of different explants and media composition for efficient somatic embryogenesis in sugarcane (Saccharum oficinarum). Pakistan journal of Botany, 39(6), 1961-1977.

Anbalagan, S., Kalmani, A. \& Sakila, M. (2000). In vitro propagation of sugarcane: nature of callus, direct regeneration, regeneration through callus and morphological variations. Research on Crops, 2, 13 8-140.

Ather, A., Khan, S., Rehman, A. \& Nazir, M (2009). Optimization of the protocols for callus induction, regeneration and acclimatization of sugarcane cv. thatta- 10. Pakistan journal of Botany, 41(2), 8 15-820.

Badawy, O. M., Nasr, M. I. \& Alhendawi, R. A. (2008). Response of sugarcane (Saccharum species hybrid) genotypes to embryogenic callus induction and in vitro salt stress. Sugar Tech, 10(3), 243-247.

Escalona, M., Castillo, R., Concepcion, O., Barroto, C.G., Lorenzo, J.C., Daquinta, M.A. et. al. (1995). Influence of two callus types on the establishment of cell suspensions in sugarcane (Sacchrum spp.). Centro Agricola, 22, 63-70.

Fitch, M.M.M. \& Moore, P.H. (1990). Comparison of 2, 4-D and picloram for selection of long-term totipotent green callus cultures of sugarcane. Plant Cell, Tissue and Organ Culture, 20, 157-168.

Gandonou,C., Abrini, J., Idaomar, M. \& Senhaji, N.S. (2005). Response of sugarcane (Saccharum sp.) varieties to embryogenic callus induction and in vitro salt stress. African Journal of Biotechnology 4, 350-354.

Ho, W.J. \& Vasil, I.K. (1983). Somatic embryogenesis in sugarcane (Saccharum oficinarum L.) I. The morphology and physiology of callus formation and the ontogeny of somatic embryos, 118, 169-180.

Manickavasagam, M. \& Ganapathi, A. (1998). Direct somatic embryogenesis and plant regeneration from leaf explants of sugarcane. Indian Journal of Experimental Biology, 36, 832-835.

Murashige, T. \& Skoog, F. (1962). A revised medium for rapid growth and bioassay with tobacco tissue culture. Physiol Plant, 15,473-487.

Nadar, M., Soepraptopo, S., Heinz, D. J. \& Ladd, S. L. (1978). Fine Structure of Sugarcane (Saccha rum sp.) Callus and the Role of Auxin in Embryogenesis. Crop Sciences, 18, 210-216.

Ramanand, Kureel, N., Subhanand, N., Lal, M. \& Singh, S. B. (2005). Plantlet regeneration through leaf callus 
culture in sugarcane. Sugar Tech, 8(1), 85-87.

[Online] Available: http://prr.hec.gov.pk/Chapters/1 370-5.pdf

[Online] Available: http://www.thebioenergysite.com/articles/33 5/pakistan-sugar-annual-report-2009.

Table 1. Sugarcane cultivars used in the experiment

\begin{tabular}{|c|c|c|c|c|c|c|c|c|c|c|c|c|c|c|c|c|}
\hline $\begin{array}{l}\text { Variet } \\
\text { y Code }\end{array}$ & V1 & V2 & V3 & V4 & V5 & V6 & V7 & V8 & V9 & V10 & V11 & V12 & V13 & V14 & V15 & V16 \\
\hline Variet & NSG & JSG & NSG- & NSG & NSG- & HSF- & HSF- & HSF- & $\mathrm{CSSG}$ & $\mathrm{CSSG}$ & SPSG & $\mathrm{BF}$ & M- & CP- & SPF & SPF- \\
\hline $\begin{array}{c}\mathbf{y} \\
\text { Name }\end{array}$ & 555 & 6 & 311 & 59 & 646 & 240 & 242 & 245 & 66 & 676 & 26 & 162 & 93 & $77 / 400$ & 234 & 213 \\
\hline
\end{tabular}

Table 2. Media compositions used in the experiment

\begin{tabular}{|c|c|c|}
\hline Medium & \multicolumn{2}{|c|}{ Medium composition } \\
\hline & Callogenesis & $\begin{array}{l}\text { Somatic embryogenesis and } \\
\text { Plant regeneration }\end{array}$ \\
\hline SC1 & $\mathrm{MS}+2,4-\mathrm{D} 1.0 \mathrm{mg} / \mathrm{l}$ & \\
\hline SC2 & $\mathrm{MS}+2,4-\mathrm{D} 2.0 \mathrm{mg} / \mathrm{l}$ & \\
\hline SC3 & $\mathrm{MS}+2,4-\mathrm{D} 3.0 \mathrm{mg} / \mathrm{l}$ & \\
\hline SC4 & $\mathrm{MS}+2,4-\mathrm{D} 4.0 \mathrm{mg} / \mathrm{l}$ & \\
\hline SS 1 & & $\mathrm{MS}+2,4-\mathrm{D}+\mathrm{BAP} 1+1 \mathrm{mg} / \mathrm{l}$ \\
\hline SS2 & & $\mathrm{MS}+2,4-\mathrm{D}+\mathrm{BAP} 2+1 \mathrm{mg} / 1$ \\
\hline SS3 & & $\mathrm{MS}+2,4-\mathrm{D}+\mathrm{BAP} 2+2 \mathrm{mg} / \mathrm{l}$ \\
\hline SS4 & & MS+2,4-D+BAP 2+3 mg/l \\
\hline SS5 & & IAA+BAP $1+1 \mathrm{mg} / \mathrm{l}$ \\
\hline SS6 & & IAA+BAP 2+1 mg/l \\
\hline SS7 & & $\mathrm{IAA}+\mathrm{BAP} 2+2 \mathrm{mg} / \mathrm{l}$ \\
\hline SS8 & & $\mathrm{IAA}+\mathrm{BAP} 2+3 \mathrm{mg} / \mathrm{l}$ \\
\hline
\end{tabular}




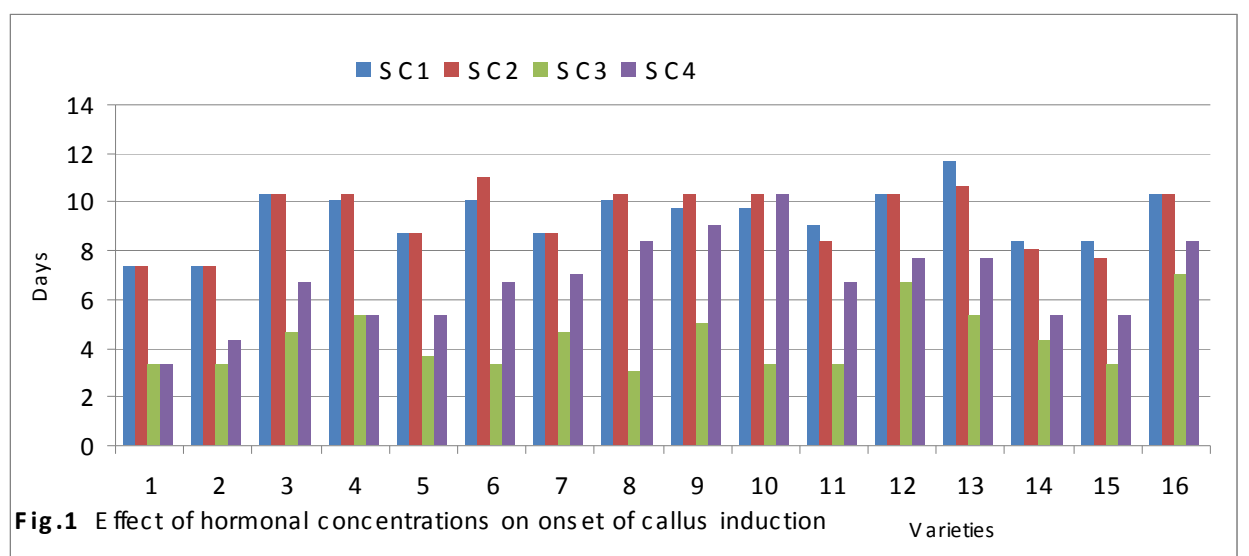

Figure 1. Effect of hormonal concentrations on onset of callus induction

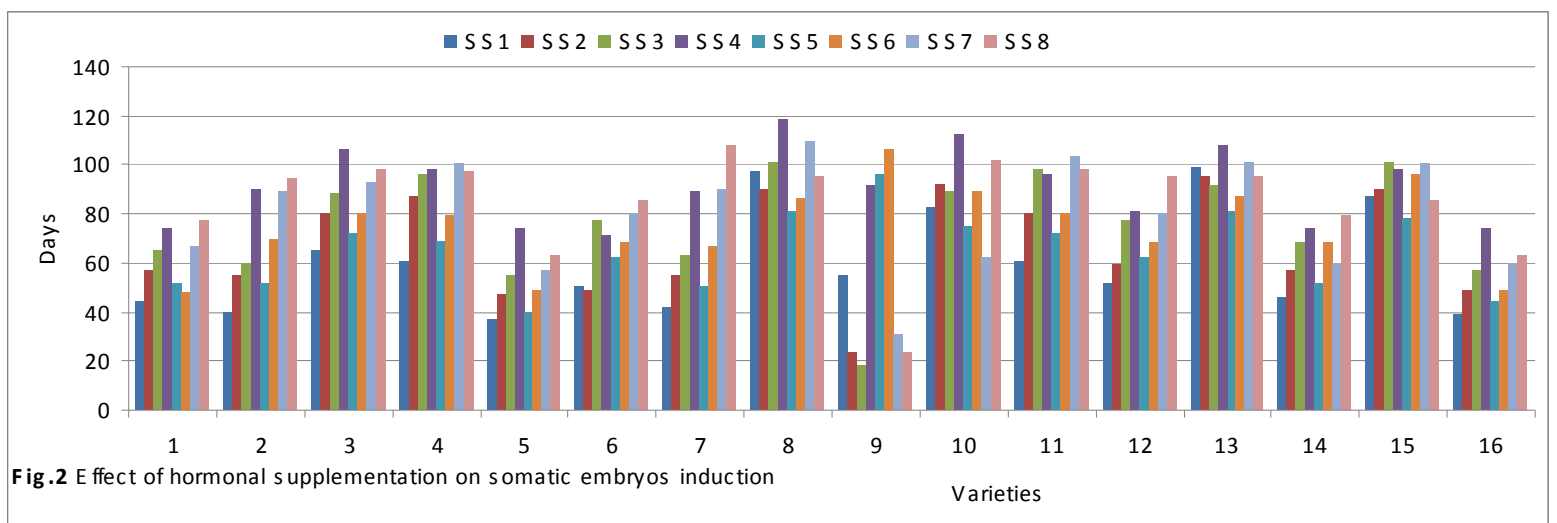

Figure 2. Effect of hormonal supplementation on somatic embryos induction

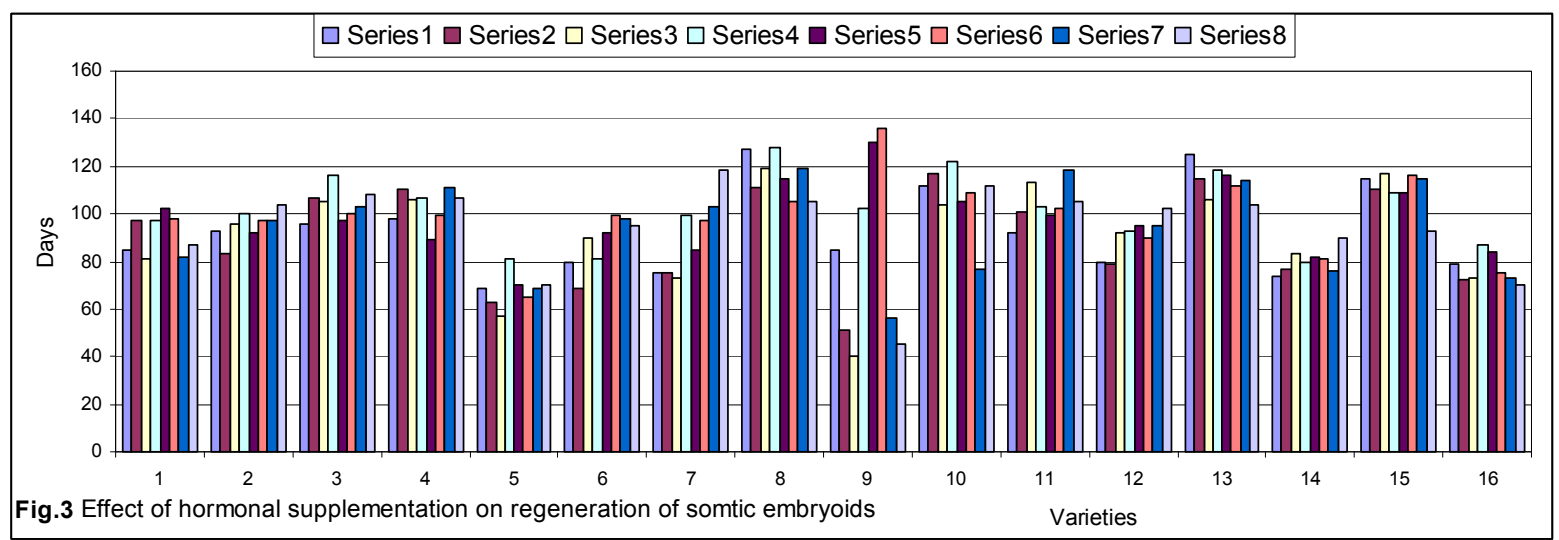

Figure 3. Effect of hormonal supplementation on regeneration of somtic embryoids 

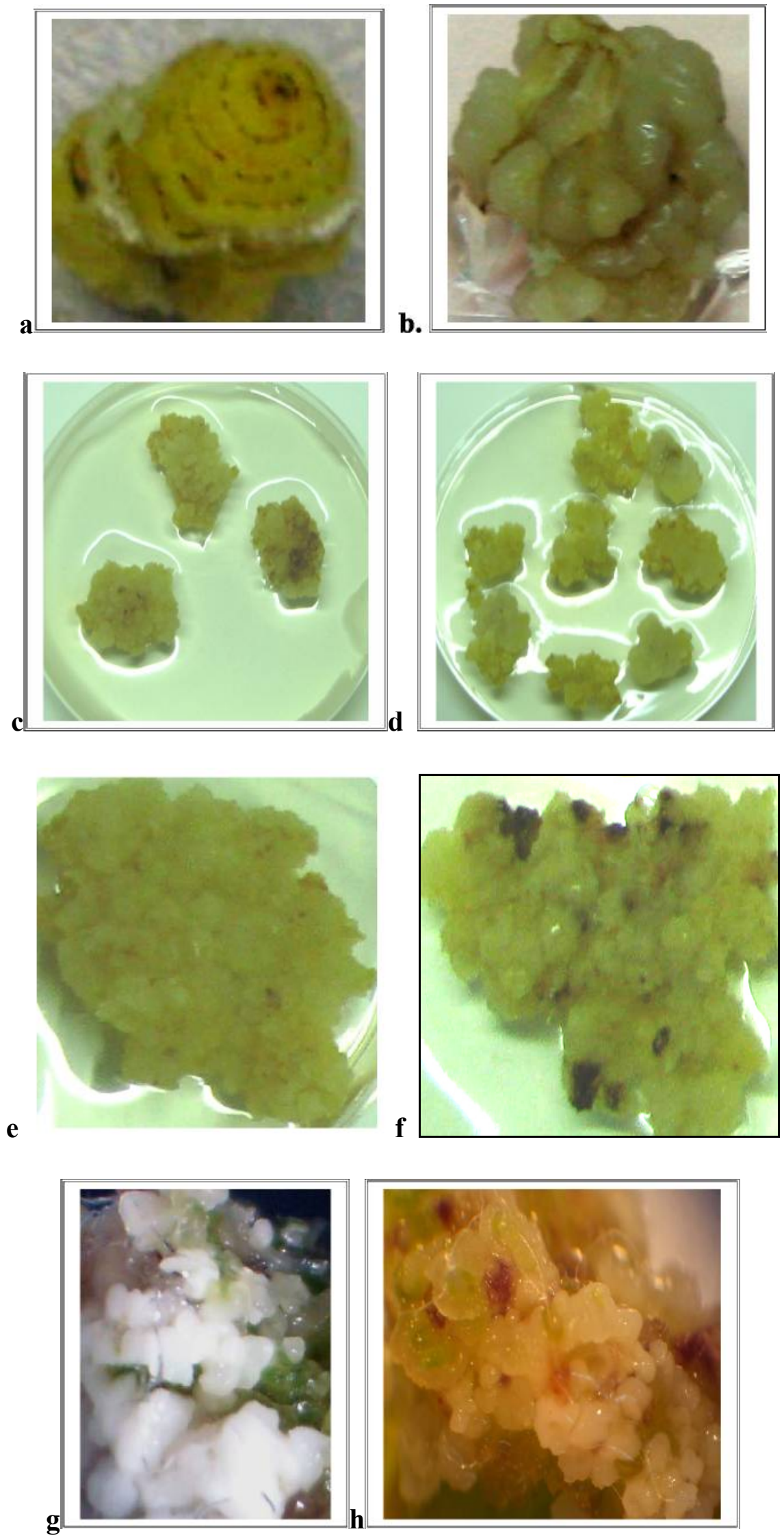

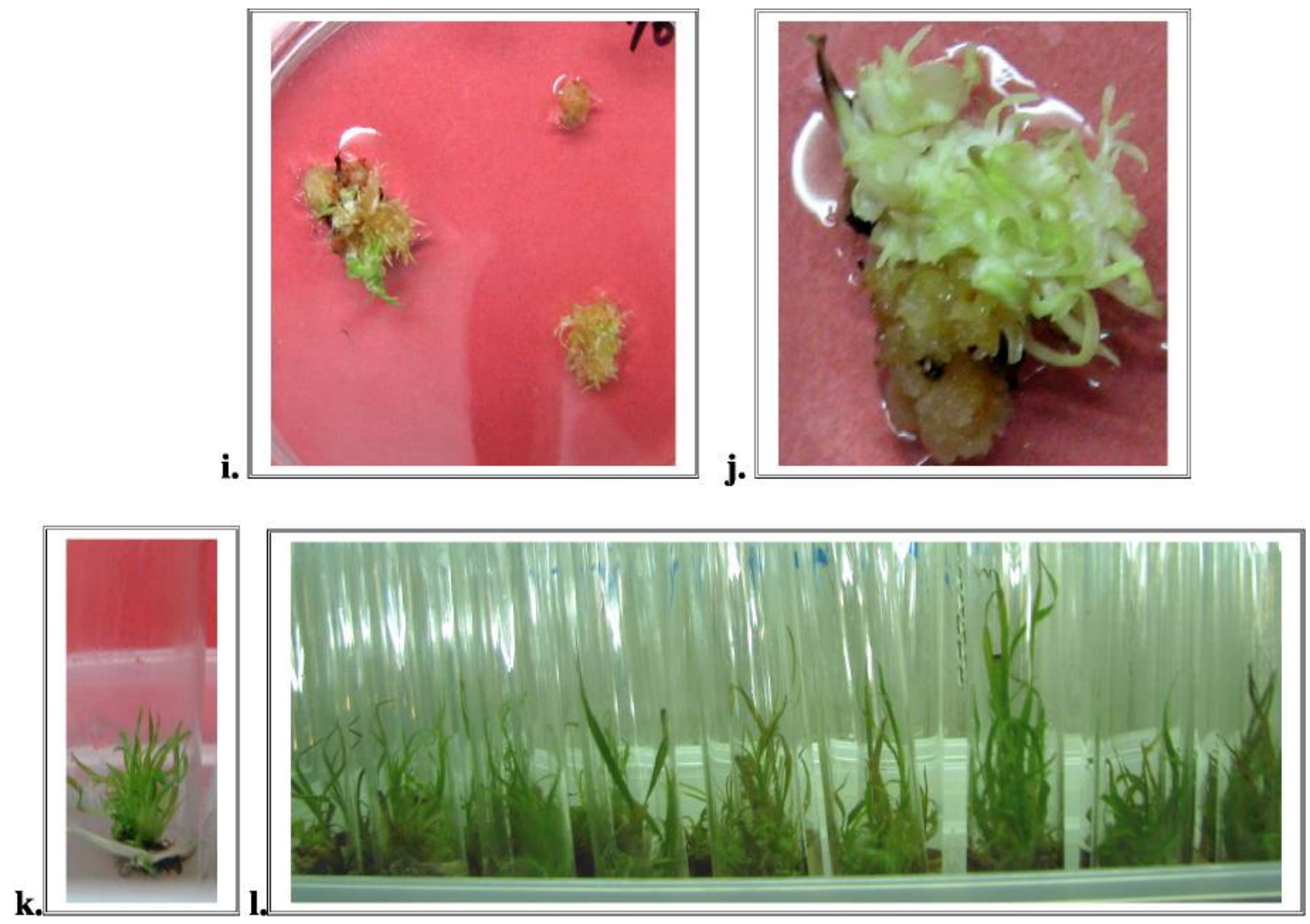

Figure 4. (a to 1)

a. 5 days old culture on MS+2,4-D 3mg/l showing nodular structure at cut edges (HSF-245). b. 21 days old callus in MS+2,4-D 4mg/l (HSF-240). c. 4 weeks old callus on MS+2,4-D 3mg/1 (NSG-555) d. 4 weeks old callus on MS+2,4-D 3mg/l (SPF-213) e. 5 week old callus of BF-162 f. 6 week old CP-77/400 g. white somatic embryoids on yellow callus of SPF-234 in 2,4-D+BAP $2+1 \mathrm{mg} / \mathrm{l} \mathrm{h}$. minute plantlets ready to emerge from nodular structure of NSG-31 1 in 2,4-D+BAP $1+1 \mathrm{mg} / 1$ i. plant regeneration from callus of CSSG-676 in 2,4-D+BAP $2+2 \mathrm{mg} / \mathrm{l}$ j. plant regeneration in SPF-234 in IAA+BAP 2+3 mg/l. k. 3 months old plant of M-93 1.4 months old plants of different varieties in table- 1 . 